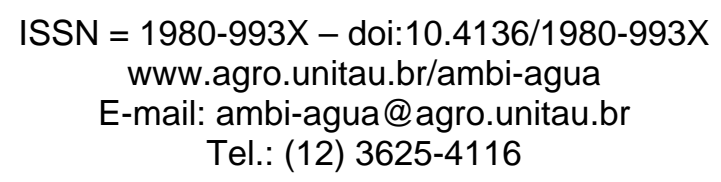

\title{
Heterogeneidade espacial e temporal da qualidade da água no reservatório Rio das Pedras (Complexo Billings, São Paulo)
} (doi:10.4136/ambi-agua.101)

\author{
Paula Regina Padial'; Marcelo Pompêo' ${ }^{1}$ Viviane Moschini-Carlos ${ }^{2}$ \\ ${ }^{1}$ USP, Instituto de Biociências, Departamento de Ecologia \\ E-mail: paulapadial@usp.br; mpompeo@ib.usp.br \\ ${ }^{2}$ Universidade Estadual Paulista, Campus de Sorocaba \\ E-mail: viviane@sorocaba.unesp.br
}

\section{RESUMO}

Este trabalho teve como objetivo avaliar em escalas espacial (vertical e horizontal) e temporal as características limnológicas do Reservatório Rio das Pedras (Complexo Billings, São Bernardo do Campo, SP - Brasil). Nos meses de março e outubro de 2004 foram amostradas em perfil três estações no reservatório. As variáveis analisadas foram: temperatura, condutividade elétrica e $\mathrm{pH}$, com sonda multiparâmetros; concentrações de amônio, nitrito, nitrato, fosfato, ortosilicato, fósforo total, clorofila-a e feofitina, por método espectrofotométrico; oxigênio dissolvido por método titulométrico; além das concentrações de sólidos totais e material em suspensão. Para análise estatística dos dados foi aplicada a ACP (Análise de Componentes Principais). A heterogeneidade temporal observada foi conseqüência das diferenças de temperatura, que geraram estratificação térmica, química e biológica, no mês de março. As diferenças espaciais verticais também resultaram da estratificação térmica. As maiores discrepâncias das características limnológicas, em relação ao padrão de distribuição espacial horizontal, foram obtidas na estação 1, e são diretamente relacionadas à influência das águas provenientes do reservatório Billings. De acordo com a CONAMA 357/05, para o mês de outubro de 2004 as águas do reservatório estão em conformidade com a Classe 3. Para o mês de março, na estação 3 os valores estão abaixo do estabelecido, conferindo não conformidade para a Classe 3.

Palavras-chave: estratificação; limnologia; ACP.

\section{Spatial and temporal heterogeneity of water quality in Rio das Pedras reservoir (Billings Complex, São Paulo State)}

\section{ABSTRACT}

The objective of the present study was to evaluate spatial and temporal patterns of limnological characteristics of the Rio das Pedras Reservoir (Billings Complex, São Bernardo do Campo, São Paulo - Brazil). Profile samples were taken at three stations during two periods (March and October, 2004). The variables analyzed were: temperature, electrical conductivity, $\mathrm{pH}$, with multiparameter probe; concentration of ammonium, nitrite, nitrate, phosphate, orthosilicate, total phosphorus, chlorophyll-a and phaeophytin, by spectrophotometric method; dissolved oxygen by titrimetric method; beyond concentrations of total solids and suspended material. PCA (Principal Components Analyses) was applied for the statistical analyses. The temporal heterogeneity observed was a consequence of differences in temperature observed in the month of March, which generated thermal, chemical and biological stratification. The vertical spatial differences also resulted from the thermal stratification. The largest discrepancies in the limnological characteristics, in relation to the pattern of horizontal spatial distribution, were obtained in station 1, and are directly 
related to the influence of the incoming waters of the Billings reservoir. According to CONAMA 357/05, for the month of October, 2004, the waters of the reservoir were in accordance with Class 3. In March, the values for station 3 were below the standards established, indicating non-conformity with Class 3.

Keywords: stratification; limnology; PCA.

\section{INTRODUÇÃO}

A construção de reservatórios para diversos fins é uma das importantes intervenções humanas nos sistemas naturais (Tundisi, 1988). Devido ao aumento populacional e à crescente demanda por recursos hídricos e energéticos, os pequenos sistemas inicialmente utilizados foram substituídos por grandes empreendimentos, empregados na produção de energia elétrica, recreação, transporte, produção de biomassa, irrigação e suprimento de água.

$\mathrm{O}$ estudo de reservatórios apresenta grande interesse do ponto de vista científico, uma vez que permite acompanhar a colonização e a evolução das comunidades no ecossistema criado, contribuindo para compreender problemas básicos em ecologia. Além disso, o estudo de reservatórios proporciona uma base fundamental para o gerenciamento da qualidade da água e das bacias hidrográficas e para o planejamento dos usos múltiplos do sistema (Tundisi, 1999). Como sistemas complexos, os reservatórios apresentam um padrão dinâmico, com rápidas mudanças em seus mecanismos de funcionamento e gradientes horizontais e verticais (Tundisi, 1999).

A natureza dendrítica e a presença de tributários com distintas qualidades de água podem gerar heterogeneidade espacial horizontal e vertical nas características limnológicas do reservatório (Thorton et al., 1990), refletindo na composição química, nas características físicas e na distribuição espacial das comunidades (Nogueira, 1999). O principal fator responsável pelo surgimento da heterogeneidade vertical em reservatórios é o fenômeno da estratificação térmica (Tundisi, 1988), seguida por estratificações químicas e biológicas.

De acordo com Cardoso-Silva (2008), o estabelecimento de padrões de heterogeneidade espacial e temporal em reservatórios é uma ferramenta importante na elaboração de propostas de manejo. A qualidade da água nos reservatórios pode variar espacial e temporalmente, e isto pode levar a diferentes maneiras de se tratar e operar o sistema, buscando atender aos usos múltiplos, como o abastecimento público e à escolha de locais para a recreação como natação e pesca.

Através de programas de monitoramento, como instrumento do controle quantitativo e qualitativo dos recursos hídricos, é possível avaliar a evolução da qualidade dos corpos d'água e tomar medidas que permitam minimizar os impactos ao meio ambiente (Braga et al., 1999).

O gerenciamento da qualidade da água exige que sejam estabelecidas formas de acompanhar a variação de indicadores da qualidade da água, permitindo observar alterações nas condições de um corpo hídrico (Porto, 1991). Desta forma, é necessário que sejam definidos padrões e critérios de qualidade das águas. O Conselho Nacional do Meio Ambiente (CONAMA), por meio da Resolução do CONAMA no 357, de 17 de março de 2005 (Brasil, 2005), estabeleceu a classificação das águas doces, salinas e salobras, de acordo com seus usos preponderantes, e os parâmetros físicos, químicos e biológicos que as definem.

Com o intuito de promover o conhecimento básico do reservatório Rio das Pedras (Complexo Billings, SP) e fornecer subsídios para futuros projetos este trabalho teve como objetivo avaliar a variação de características limnológicas básicas da água em escalas espacial (vertical e horizontal) e temporal. 


\subsection{Local de estudo}

O Reservatório Rio das Pedras (São Bernardo do Campo, São Paulo), está localizado no Alto da Serra do Mar a $727 \mathrm{~m}$ de altitude média, acerca das coordenadas $23^{\circ} 5^{\prime} \mathrm{S}$ e $46^{\circ} 29^{\prime} \mathrm{W}$ (Figura 1). Foi construído no ano de 1926, com o objetivo de receber as águas provenientes do represamento do Rio Grande, para posterior geração de energia elétrica na Usina Henry Borden, em Cubatão. A partir década de 30, para o aumento da capacidade de geração da Usina Henry Borden, foram realizadas as obras de retificação e reversão do rio Pinheiros, a formação do reservatório Billings, a construção das usinas elevatórias de Pedreira, Traição e da barragem reguladora Billings-Pedras.

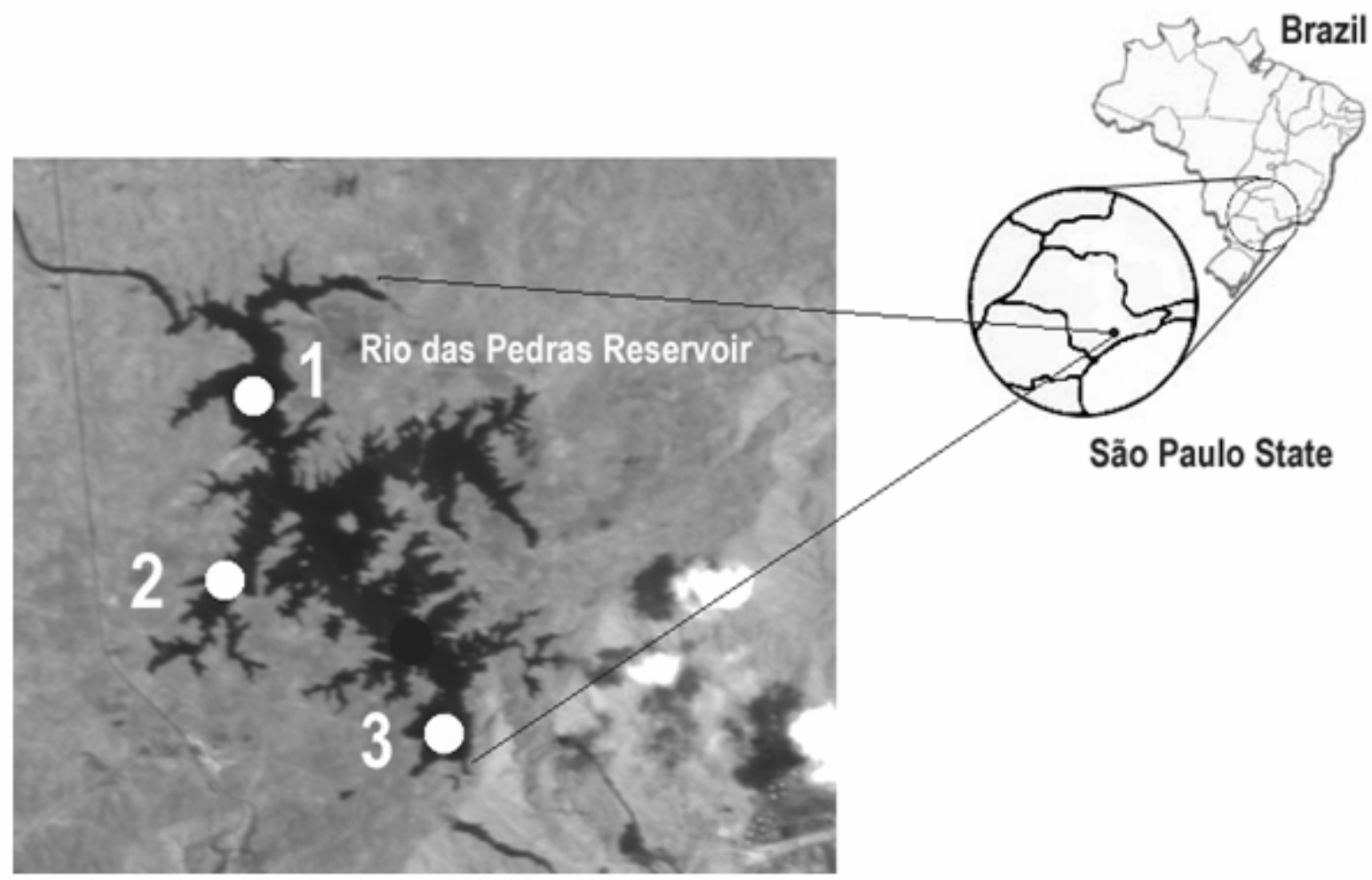

Figura 1. Localização das estações de coleta no reservatório Rio das Pedras.

A barragem Billings-Pedras localiza-se entre o reservatório Billings e o Canal BillingsPedras. Essa estrutura tem como finalidade o controle do fluxo de água do reservatório Billings para o reservatório do Rio das Pedras.

O complexo Henry Borden, localizado no sopé da Serra do Mar, em Cubatão, é composto por duas usinas de alta queda $(720 \mathrm{~m})$, denominadas de Externa e Subterrânea, com 14 grupos de geradores acionados por turbinas, perfazendo uma capacidade instalada de 889 MW, para uma vazão de $157 \mathrm{~m}^{3} / \mathrm{s}$. Desde outubro de 1992, a operação desse sistema vem atendendo às condições estabelecidas na Resolução Conjunta SMA/SES 03/92, de 04/10/92, atualizada pela Resolução SEE-SMA-SRHSO-I, de 13/03/96, que só permite o bombeamento das águas do rio Pinheiros para o reservatório Billings para controle de cheias, reduzindo em $75 \%$ aproximadamente a energia produzida em Henry Borden. Atualmente, está em testes um sistema de flotação das águas do rio Pinheiros, para que este possa ser novamente lançado no reservatório Billings, a fim de aumentar a produção hídrica e a geração de energia em Henry Borden. As águas do reservatório Rio das Pedras também são utilizadas para fins recreacionais (pesca).

Após a passagem pelas turbinas da Usina Hidrelétrica Henry Borden, as águas são destinadas ao abastecimento público pela Estação de Tratamento de Água de Cubatão. 
O reservatório tem como principais afluentes os rios das Pedras, Zanzalá, Ribeirão Fresco, além do canal de ligação Billings-Pedras (EMAE, 2004). Este reservatório não está incluído na rede de monitoramento de qualidade da água da CETESB (2008).

A temperatura na região do reservatório Rio das Pedras apresenta padrão anual com tendência de menores valores nos meses de abril a setembro (Figura 2, I). A cota de operação normal do reservatório está entre 727,60 e 727,00 m, representando a 727,00 m um volume de $26,859 \mathrm{hm}^{3}$ e um espelho de água de $6,446 \mathrm{~km}^{2}$. De janeiro ao final de abril de 2004 , o reservatório operou abaixo de 727,00 $\mathrm{m}$, sendo que a partir do início de maio operou com valores acima de 727,00 m (Figura 2, II). De maneira geral, as alterações de cota refletem as descargas a montante e a jusante (Figura 2, V e VI). Relativo à precipitação pluviométrica, para os anos de 1995 a 2003, o total mensal médio demonstra tendência de menores valores nos meses de abril a setembro (Figura 2, III). Em 2004 a precipitação total foi de 3853,8 mm, e o mês de julho apresentou valor de precipitação mensal superior à série histórica (Figura 2, IV) (EMAE, comunicação pessoal).

\section{MATERIAL E MÉTODOS}

As coletas foram realizadas nos dias 12/03/2004 e 07/10/2004, no período da manhã, em três pontos de amostragem no reservatório Rio das Pedras. As coordenadas geográficas dos pontos são: $23^{\circ} 49,916^{\prime} \mathrm{S}$ e $46^{\circ} 29,269^{\prime} \mathrm{W} ; 23^{\circ} 51,119^{\prime} \mathrm{S}$ e $46^{\circ} 29,511^{\prime} \mathrm{W} ; 2^{\circ} 51,725^{\prime} \mathrm{S}$ e $46^{\circ} 28,189^{\prime} \mathrm{W}$, para os pontos 1,2 e 3 , respectivamente (Figura 1).

Amostras de água foram coletadas em perfil, utilizando-se garrafa de Van Dohr de 5 litros. As medidas de temperatura, condutividade elétrica e $\mathrm{pH}$ foram tomadas em perfil utilizando-se sonda multiparâmetros YSI 63. A transparência da água foi determinada utilizando-se disco de Secchi (Wetzel e Likens, 1991). Os teores de nutrientes dissolvidos foram determinados segundo Koroleff (1976) - amônio, Mackereth et al. (1978) - nitrito e nitrato, Strickland e Parsons (1960) - fosfato inorgânico dissolvido e Golterman et al. (1978) - ortosilicato. As concentrações de fósforo total foram estabelecidas segundo Valderrama (1981). Para o cálculo das concentrações de oxigênio dissolvido foi empregado o método de Winkler (Golterman et al., 1978). A determinação dos teores de material em suspensão total, orgânico e inorgânico foi segundo Teixeira et al. (1965) e Tundisi (1969). O teor de sólidos totais foi determinado segundo o método de Wetzel e Likens (1991). As concentrações de clorofila-a e feofitina foram determinadas segundo Lorenzen (1967) e Wetzel e Likens (1991).

Há dois métodos tradicionalmente utilizados na determinação do íon amônio em água doce: Koroleff (1976), empregado nesta pesquisa e Solórzano e Sharp (1980). Ambos são muito utilizados no Brasil e internacionalmente aceitos na determinação do íon amônio na água doce. Os resultados apresentados pelo procedimento proposto por Solórzano e Sharp (1980), na determinação do íon amônio, são semelhantes aos valores determinados por Koroleff (1976).

Para análise estatística dos dados foi aplicada uma Análise de Componentes Principais (ACP) (Legendre e Legendre, 1998). A ACP aplicada foi a de correlação, com a matriz original de dados, pelo programa MVSP. A matriz de correlação padroniza os dados, pelo desvio padrão, de forma que as diferenças de escalas dos dados não interfiram no resultado final. 
I).

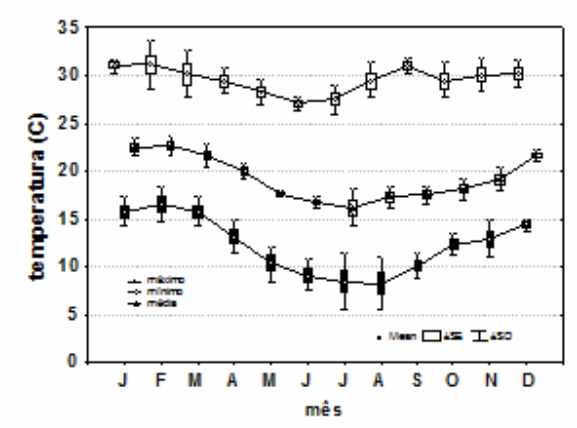

III)

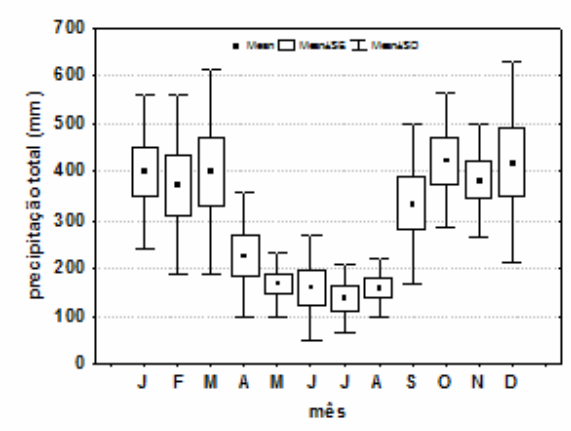

$\mathrm{Y})$

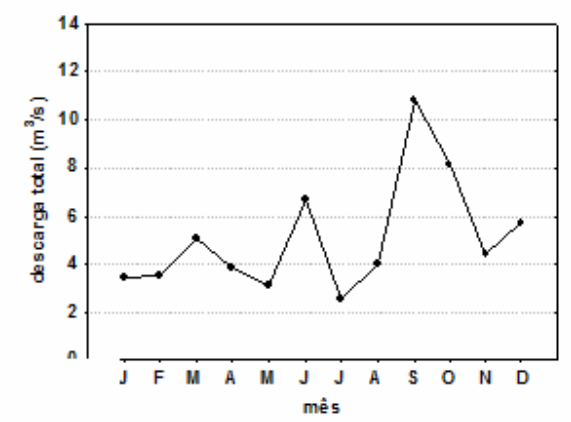

II)

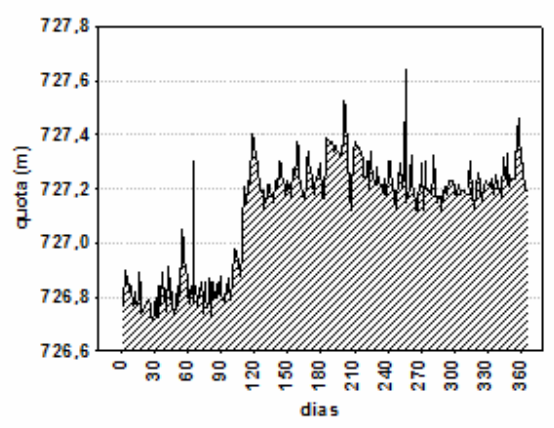

IV)

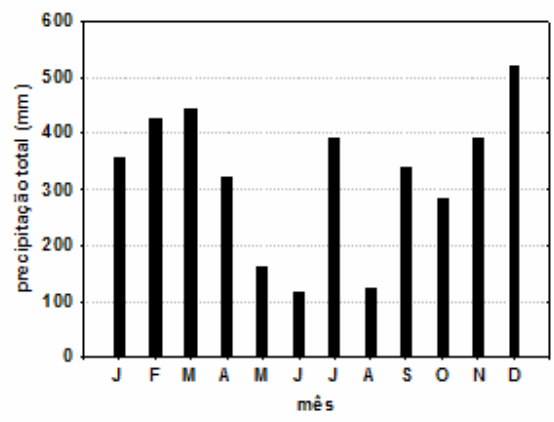

VI)

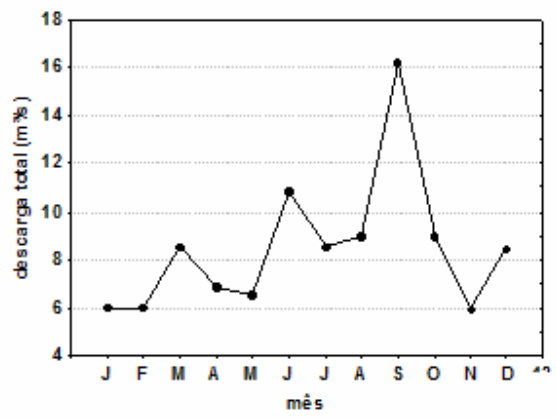

Figura 2. I) temperatura máxima (médias das máximas), mínima (médias das mínimas) e média mensal (médias das leituras efetuadas às 7,14 e 18 horas) relativa aos anos de 1995 a 2000; II) perfil diário da altura da lâmina de água no ano de 2004; III) precipitação pluviométrica total (média mensal) para os anos de 1995 a 2003; IV) precipitação pluviométrica total mensal para o ano de 2004; V) descargas mensais do canal Billings-Pedras lançadas no reservatório Rio das Pedras; VI) descargas mensais do reservatório Rio das Pedras para a usina hidrelétrica de Henry Borden - Cubatão, SP. Fonte: Empresa Metropolitana de Águas e Energia SA - EMAE, Departamento de Planejamento e Supervisão da Operação.

\section{RESULTADOS}

Os dados de temperatura, concentração de oxigênio dissolvido, $\mathrm{pH}$ e condutividade elétrica estão representados na Figura 3. Os perfis de material em suspensão total, material em suspensão orgânico, sólidos totais e material em suspensão inorgânico estão na Figura 4. As concentrações de clorofila, feofitina e silicato estão representadas na Figura 5. Os perfis de amônio e nitrato estão apresentados na Figura 6. 
PADIAL, P. R.; POMPÊO, M.; MOSCHINI-CARLOS, V. Heterogeneidade espacial e temporal da qualidade da água no reservatório Rio das Pedras (Complexo Billings, São Paulo). Ambi-Agua, Taubaté, v. 4, n. 3, p. 35-53, 2009. (doi:10.4136/ambi-agua.101)

$12 / 03 / 04$

a)

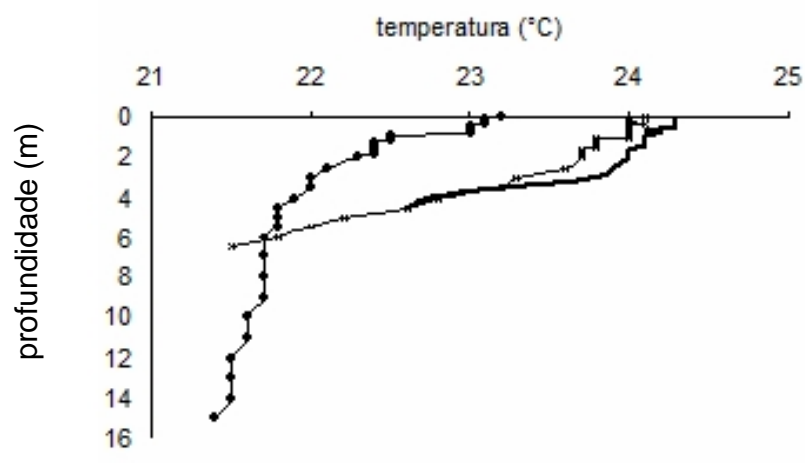

c)

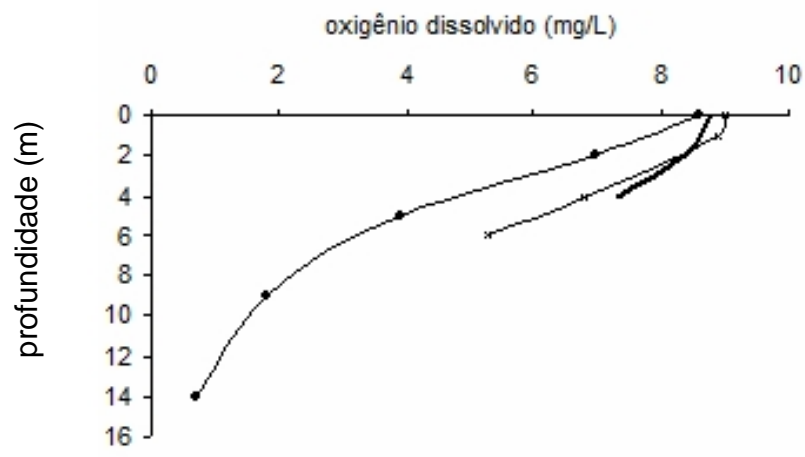

e)

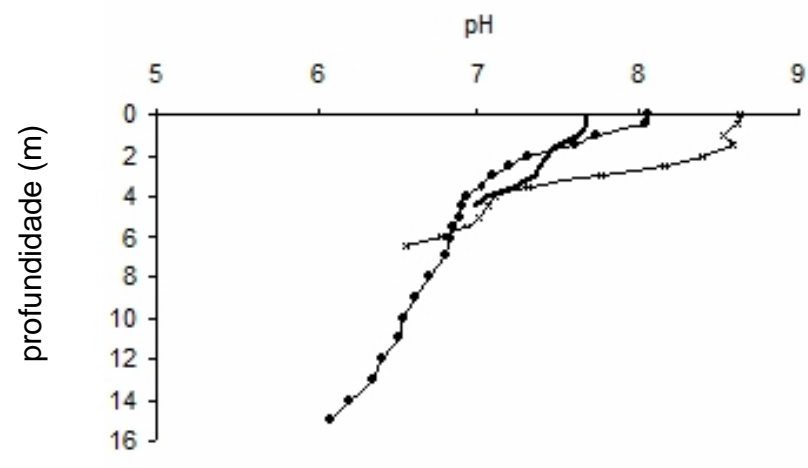

g)

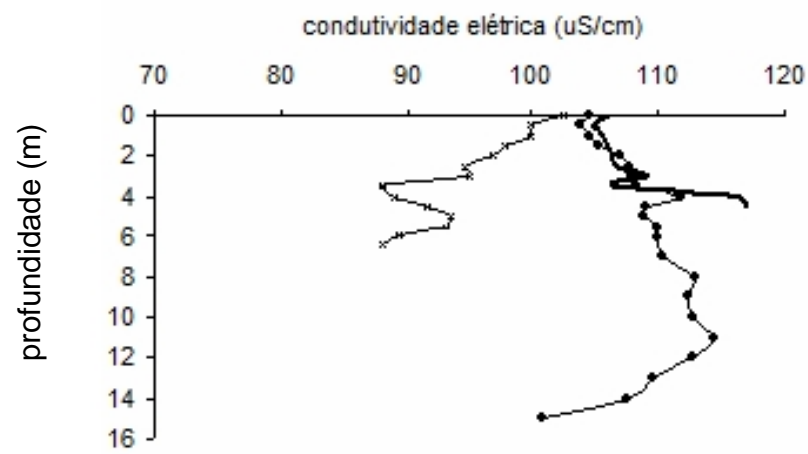

07/10/04

b)

temperatura $\left({ }^{\circ} \mathrm{C}\right)$

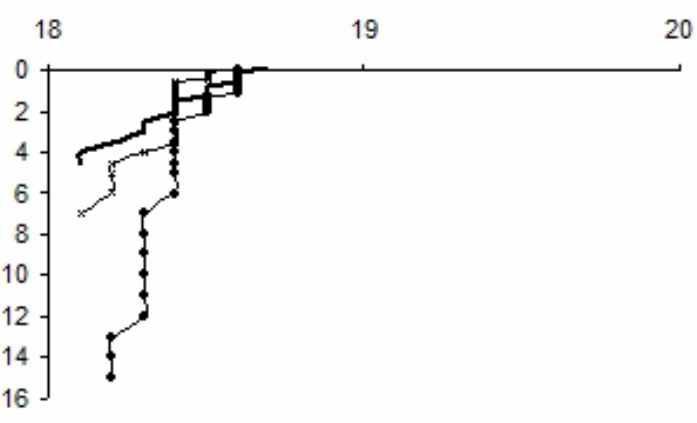

d)

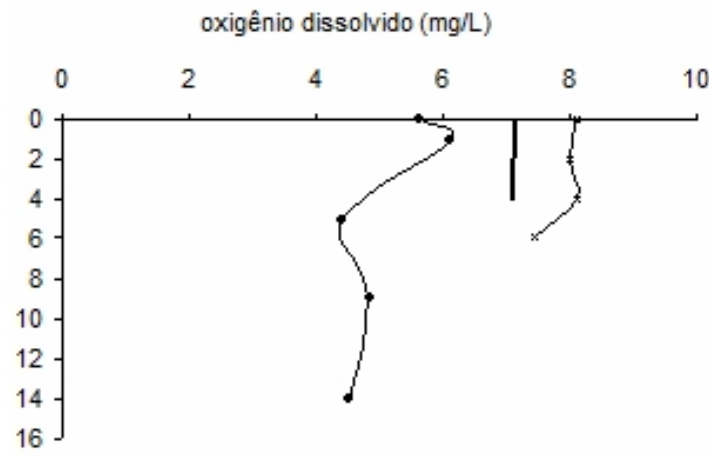

f)

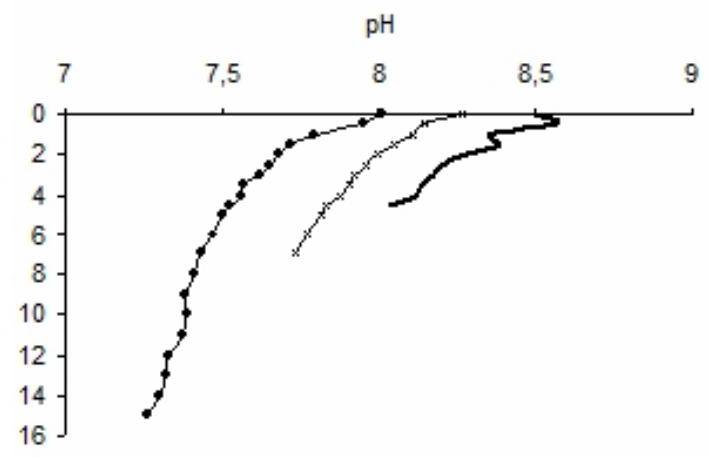

h)

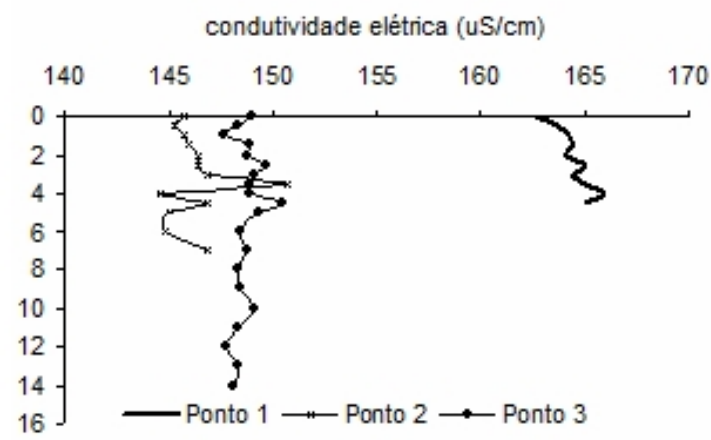

Figura 3. Perfis de temperatura (a; b), oxigênio dissolvido (c; d), pH (e; f) e condutividade elétrica (g; h), em 12/03/04 e 07/10/04, respectivamente, nos três pontos de amostragem no Reservatório Rio das Pedras. 


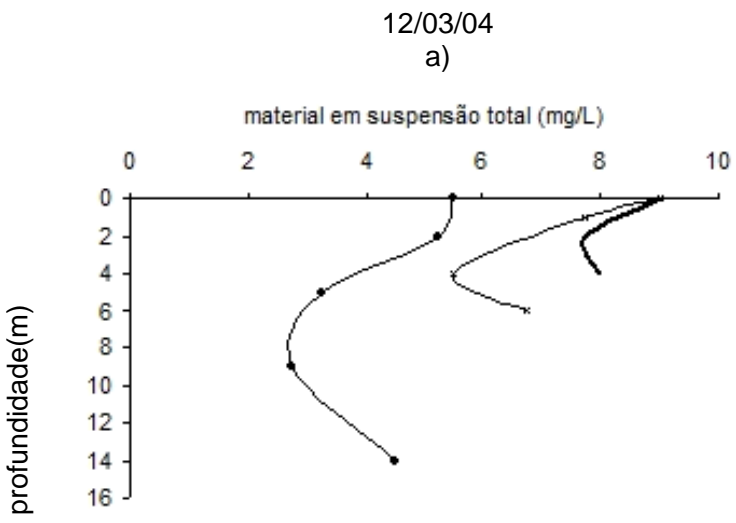

c)

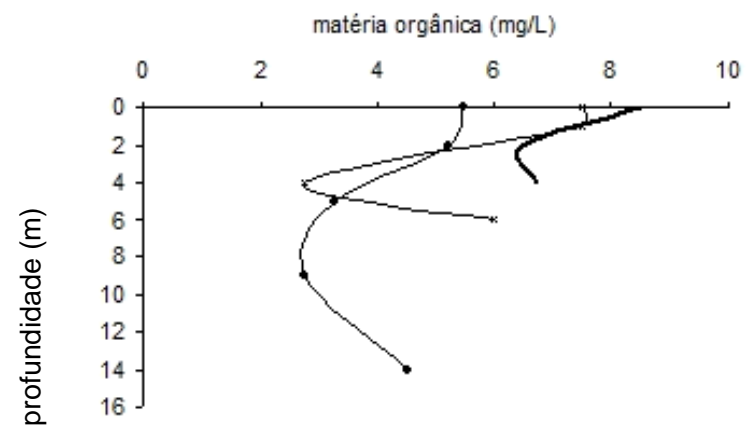

e)

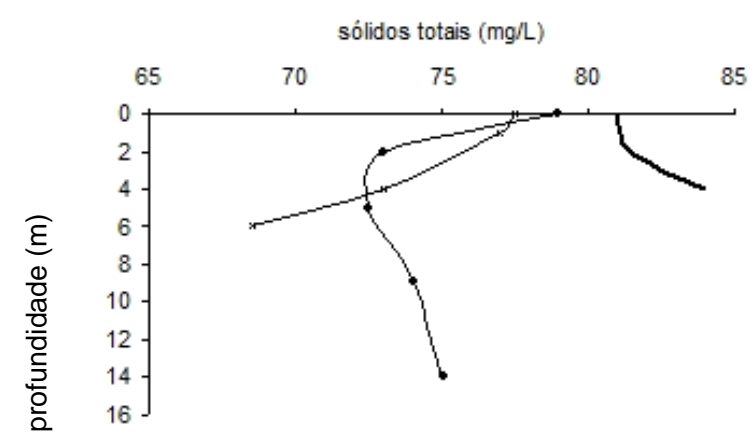

g)

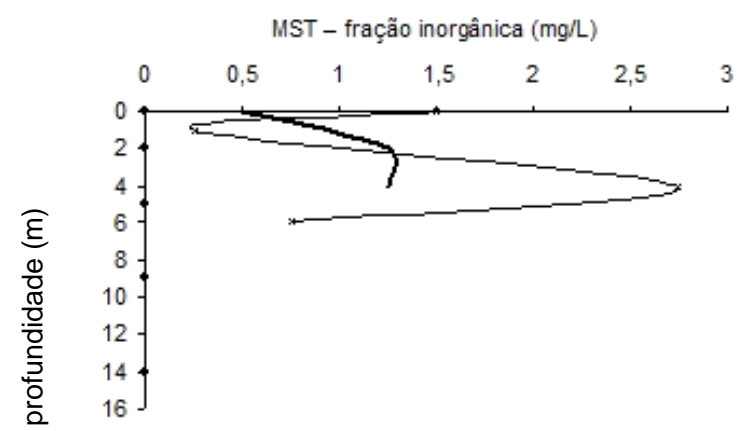

07/10/04

b)

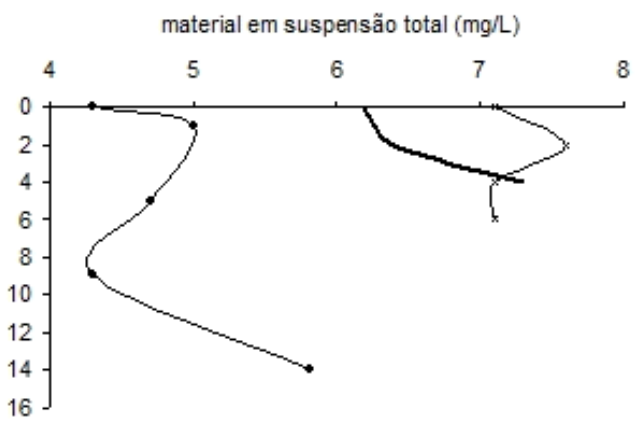

d)

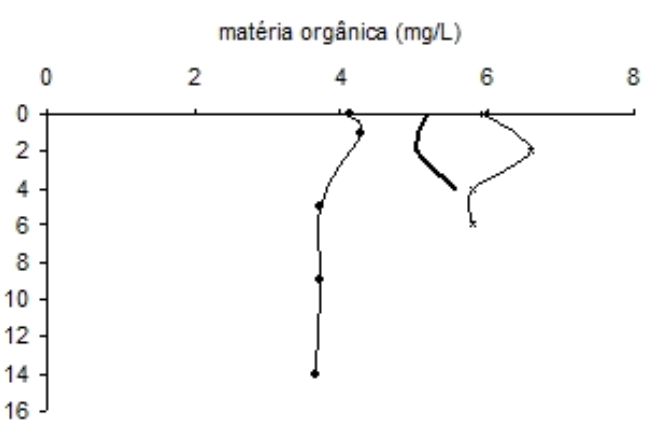

f)

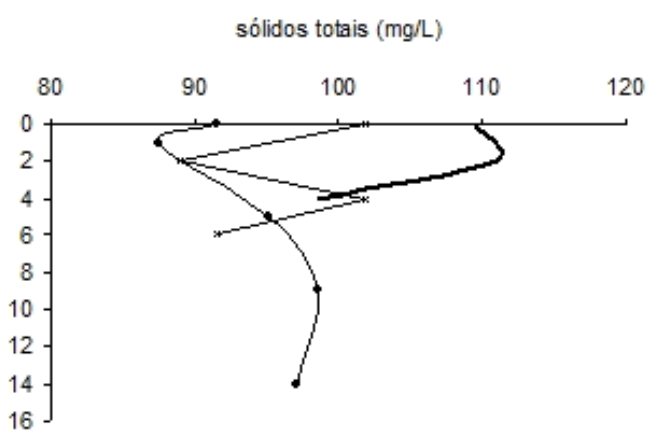

h)

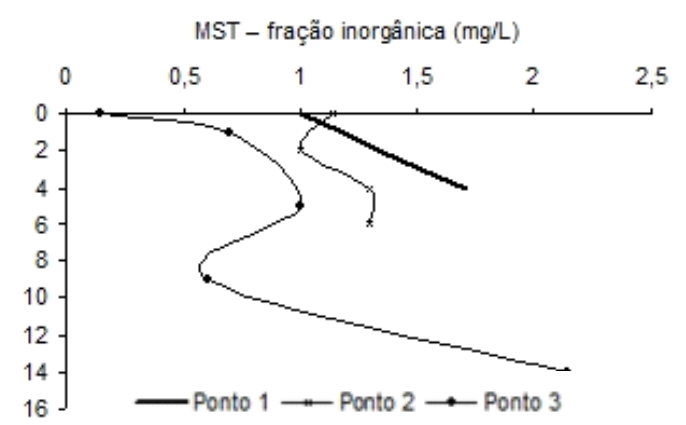

Figura 4. Perfís de material em suspensão total $(a ; b)$, material em suspensão orgânico $(c ; d)$, sólidos totais (e; f) e material em suspensão inorgânico (g; h), em 12/03/04 e 07/10/04, respectivamente, nos três pontos de amostragem no Reservatório Rio das Pedras. 
$12 / 03 / 04$

a)

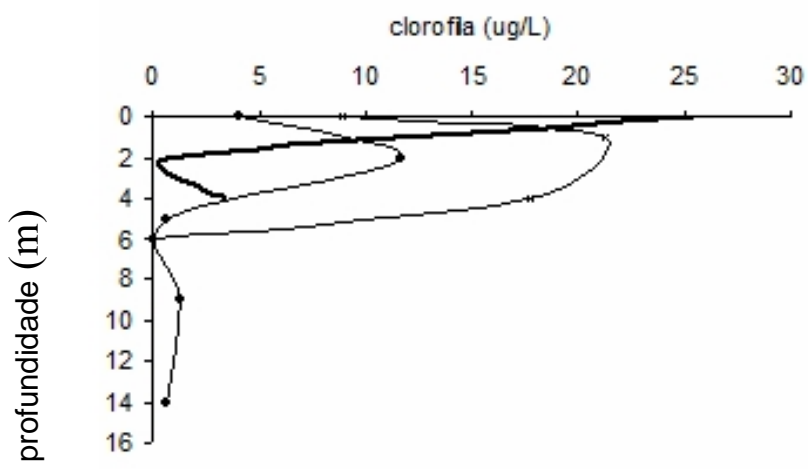

c)

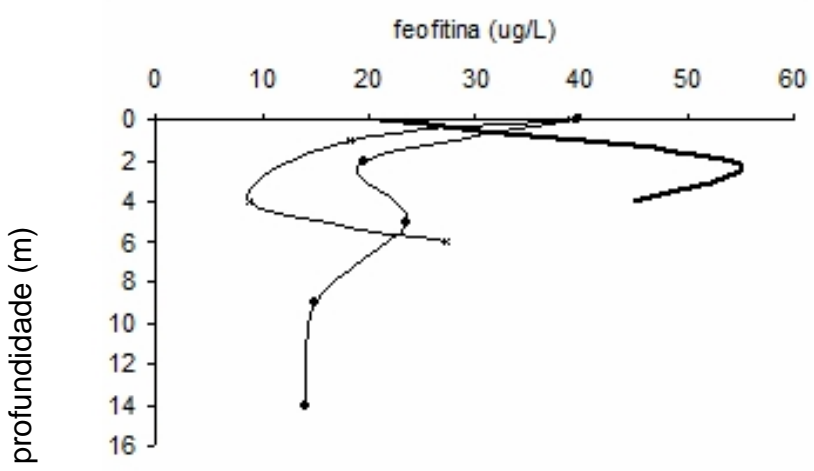

e)

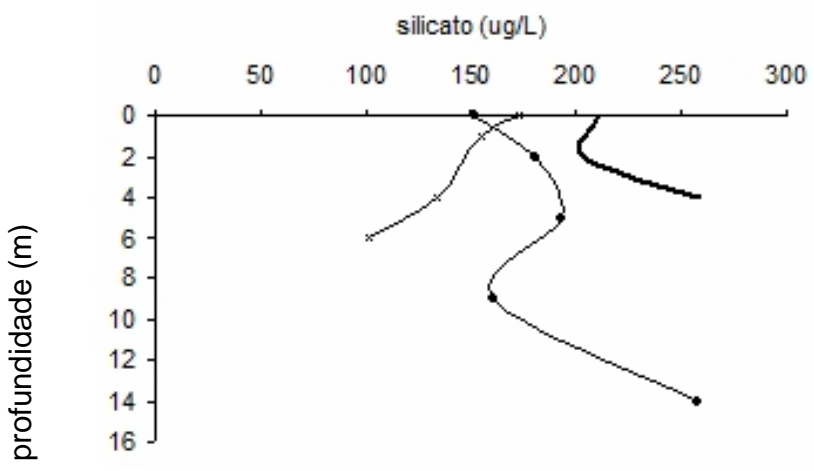

07/10/04

b)

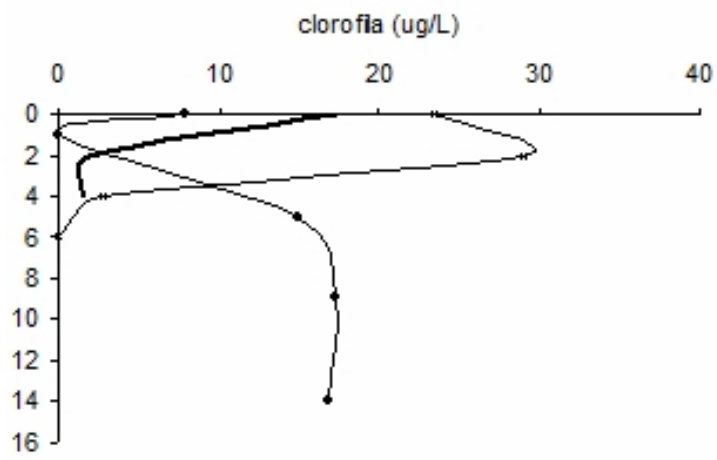

d)

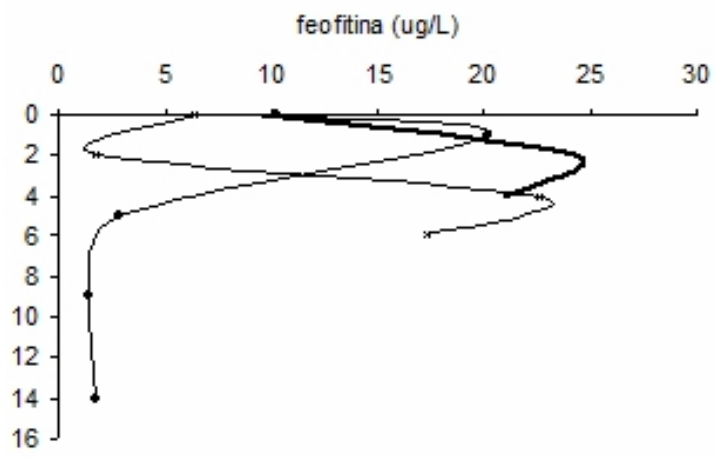

f)

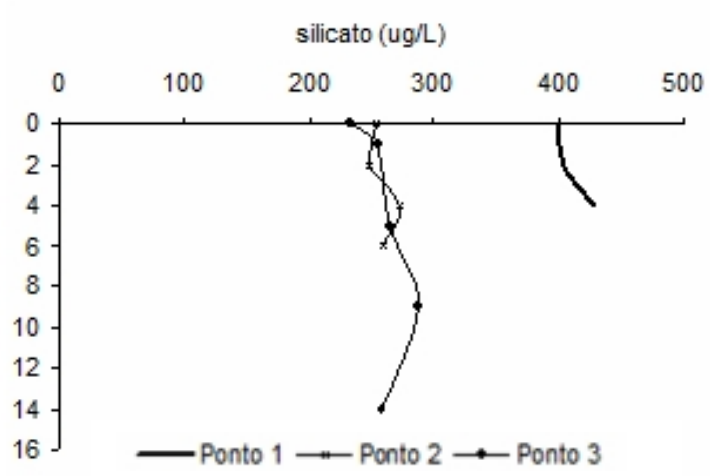

Figura 5. Perfis de clorofila (a; b), feofitina (c; d) e silicato (e; f), em 12/03/04 e 07/10/04, respectivamente, nos três pontos de amostragem no Reservatório Rio das Pedras. 
PADIAL, P. R.; POMPÊO, M.; MOSCHINI-CARLOS, V. Heterogeneidade espacial e temporal da qualidade da água no reservatório Rio das Pedras (Complexo Billings, São Paulo). Ambi-Agua, Taubaté, v. 4, n. 3, p. 35-53, 2009. (doi:10.4136/ambi-agua.101)

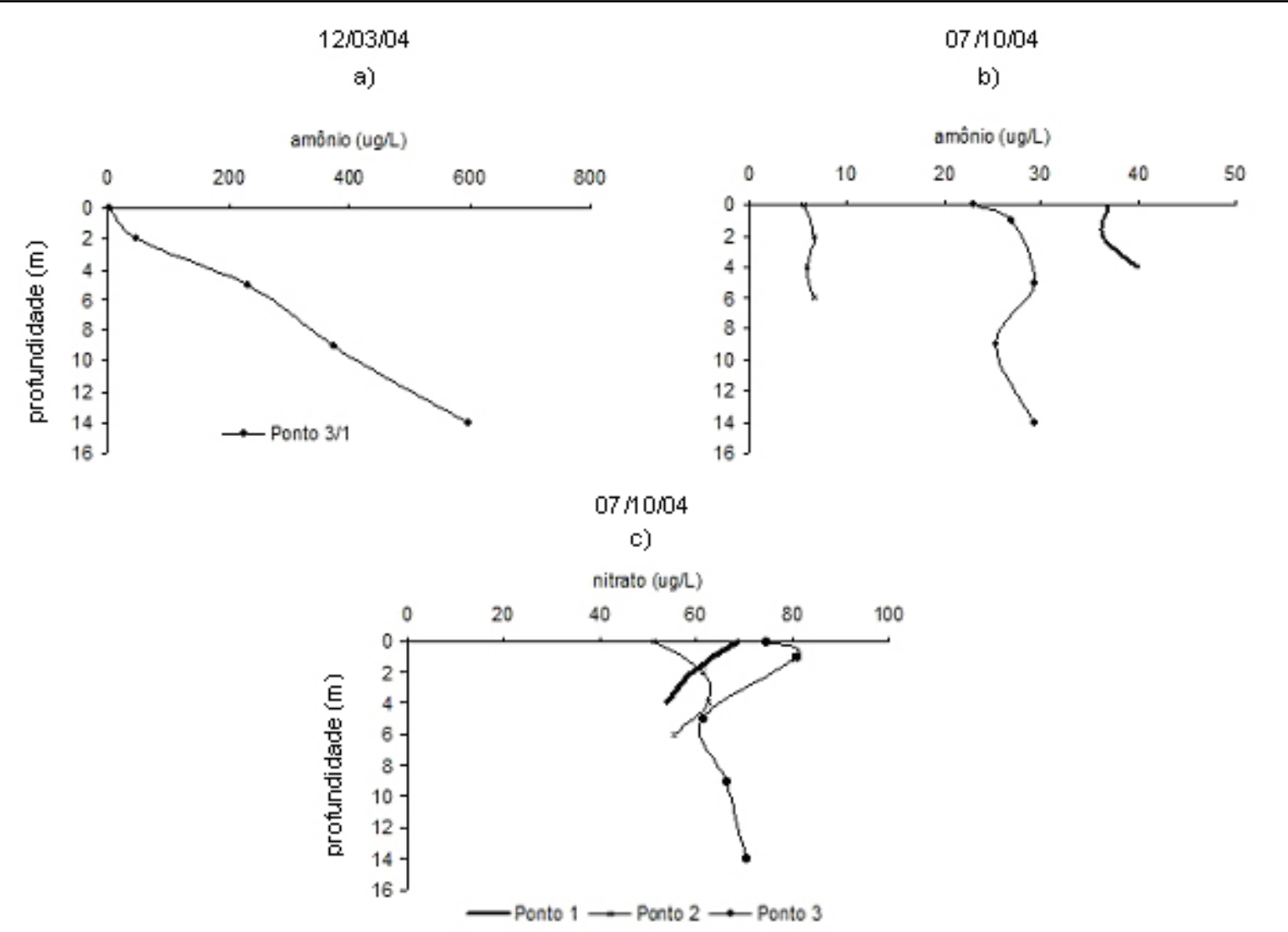

Figura 6. Perfis de amônio (a; b), em 12/03/04 e 07/10/04, respectivamente, e nitrato (c) em 07/10/04, nos três pontos de amostragem no Reservatório Rio das Pedras.

\subsection{Coleta de 12/03/2004}

Pode-se observar uma estratificação térmica nos três pontos amostrados (Figura 3a). A amplitude de variação entre os três pontos foi de $21,4^{\circ} \mathrm{C}$ a $24,3^{\circ} \mathrm{C}$. A tendência de redução nos valores em relação ao fundo também é observada para os teores de oxigênio dissolvido (Figura 3c) e nos valores de $\mathrm{pH}$ (Figura 3e). Em relação à condutividade elétrica não foi observado padrão definido com o aumento da profundidade (Figura 3g). No entanto, foram observados valores mais elevados nos pontos 1 e 3 .

Com relação ao material em suspensão total, os pontos 1 e 2 apresentaram maiores concentrações. A tendência observada é de diminuição da concentração na porção mediana da coluna d'água, seguida de novo aumento próximo ao sedimento (Figura 4a).

A concentração de matéria orgânica em suspensão foi, em média, maior no ponto 1 , e menor no ponto 3. A tendência no perfil é de redução das concentrações com o aumento da profundidade, seguida de aumento das concentrações na região do hipolímnio (Figura 4c).

Não foi observada clara tendência vertical relacionada à concentração de sólidos totais na água (Figura 4e). Verifica-se maior concentração no ponto 1 , sendo $84 \mathrm{mg} . \mathrm{L}^{-1}$ o maior valor obtido.

As profundidades de desaparecimento do disco de Secchi foram de $0,75 \mathrm{~m}$ no ponto 1 ; $0,76 \mathrm{~m}$ no ponto 2 e $1,04 \mathrm{~m}$ no ponto 3 .

No ponto 1 observa-se maior concentração de clorofila-a na porção superficial, com redução na porção mediana da coluna d'água, e pequeno aumento no fundo; já nos pontos 2 e 3 as maiores concentrações foram encontradas a $1 \mathrm{~m}$ e $2 \mathrm{~m}$ da superfície, respectivamente, reduzindo-se significativamente as concentrações com o aumento da profundidade (Figura 5a). Padrões inversos são encontrados para as concentrações de feofitina (Figura 5c).

Em relação à concentração de silicato, os maiores valores encontrados foram no ponto 1 (máximo de $258,7 \mu \mathrm{g} . \mathrm{L}^{-1}$ ), que, juntamente com o ponto 3 , apresenta tendência a aumento da 
concentração deste nutriente em direção ao hipolímnio. No ponto 2 observa-se o padrão inverso, sendo $173,8 \mu \mathrm{g} . \mathrm{L}^{-1}$ a máxima concentração encontrada (Figura 5e).

As concentrações de nitrito, nitrato, fosfato e fósforo total encontradas foram abaixo dos limites de detecção dos métodos empregados. Estes limites são: $5 \mu \mathrm{g} . \mathrm{L}^{-1}$ para nitrito; $8 \mu \mathrm{g} . \mathrm{L}^{-1}$ para nitrato; e $10 \mu \mathrm{g} . \mathrm{L}^{-1}$ para fosfato e fósforo total.

Para as concentrações de amônio foram determinadas elevadas concentrações no hipolímnio. Nos pontos 1 e 2 apenas na última profundidade amostrada foi detectada a presença de amônio. O limite de detecção do método de determinação de amônio é de $0,7 \mu \mathrm{g} . \mathrm{L}^{-1}$. O ponto 3 apresenta reduzidas concentrações na superfície, com acentuado aumento em relação ao fundo (máximo de $598 \mu \mathrm{g} . \mathrm{L}^{-1}$ ). A distribuição de amônio no ponto 3 pode ser observada na Figura 6, a.

Em relação ao material em suspensão inorgânico, não há um padrão vertical estabelecido. Nota-se no ponto 1 o aumento das concentrações em relação ao fundo. Os maiores valores foram encontrados no ponto $2\left(2,75 \mathrm{mg} . \mathrm{L}^{-1}\right)$. No ponto 3 , em todas as profundidades, não foi determinado material em suspensão inorgânico (Figura 4g).

A Análise de Componentes Principais (ACP), obtida com as variáveis coletadas no mês de março (Figura 7) demonstra heterogeneidade espacial no reservatório Rio das Pedras, uma vez que as profundidades amostradas no ponto 1 encontram-se agrupadas, e isoladas dos outros pontos de amostragem.

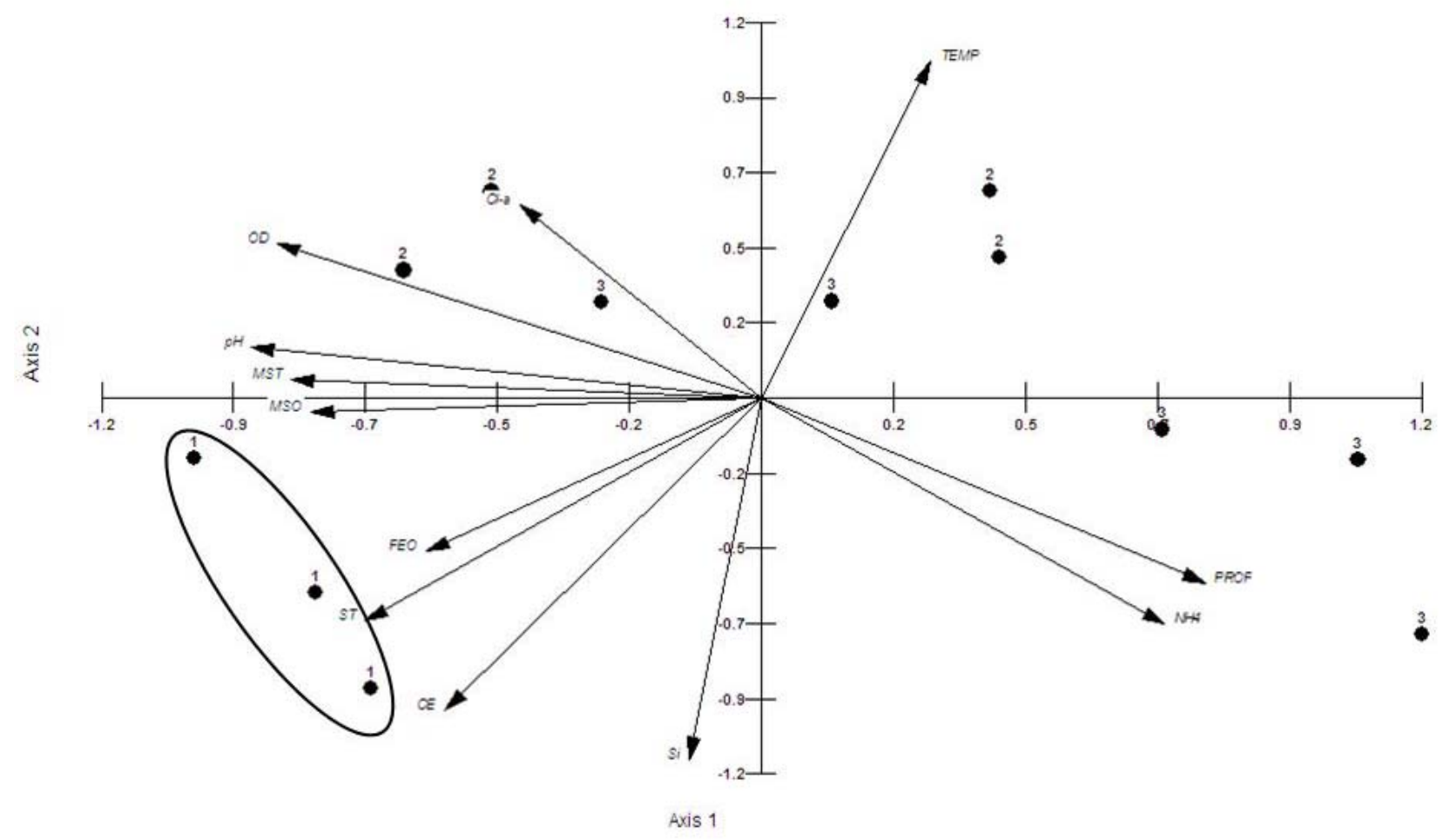

Figura 7. Resultado gráfico da Análise de Componentes Principais (ACP), obtida em três pontos de amostragem no Reservatório Rio das Pedras, em 12/03/04, onde: profundidade $=$ PROF; temperatura $=$ TEMP; condutividade elétrica $=\mathrm{CE}$; sólidos totais $=\mathrm{ST}$; clorofila-a $=\mathrm{Cl}-\mathrm{a}$; feofitina $=\mathrm{FEO}$; amônio $=$ $\mathrm{NH} 4$; silicato $=\mathrm{Si}$; oxigênio dissolvido $=\mathrm{OD}$; material em suspensão total $=\mathrm{MST}$; material em suspensão orgânico $=\mathrm{MSO}$; potencial hidrogeniônico $=\mathrm{pH}$. Observam-se em destaque (circulado) as três profundidades representativas do ponto 1, indicando a heterogeneidade espacial no reservatório.

A ACP indicou correlação positiva entre sólidos totais, condutividade elétrica e silicato; profundidade e amônio; clorofila-a, oxigênio dissolvido e pH; e correlação negativa entre temperatura e silicato. A correlação é indicada pelo ângulo obtido entre os vetores das 
PADIAL, P. R.; POMPÊO, M.; MOSCHINI-CARLOS, V. Heterogeneidade espacial e temporal da qualidade da água no reservatório Rio das Pedras (Complexo Billings, São Paulo). Ambi-Agua, Taubaté, v. 4, n. 3, p. 35-53, 2009. (doi:10.4136/ambi-agua.101)

variáveis na análise, sendo positiva quanto menor o ângulo entre os vetores, e negativa quanto maior este ângulo, que pode chegar a $180^{\circ}$.

\subsection{Coleta de 07/10/2004}

Observa-se uma homogeneidade térmica na coluna d'água, sendo a variação entre $18,1^{\circ} \mathrm{C}$ e $18,7^{\circ} \mathrm{C}$ entre os pontos amostrados (Figura $3 \mathrm{~b}$ ). A concentração de oxigênio dissolvido na água também se apresenta homogênea, com maiores valores obtidos no ponto 2 (em média $7,91 \mathrm{mg} . \mathrm{L}^{-1}$ ) (Figura 3d). No ponto 1 as concentrações obtidas foram em torno de $7,14 \mathrm{mg} . \mathrm{L}^{-1}$. No ponto 3 observa-se maior amplitude de variação, com valores entre 4,4 e 6,1 mg.L $\mathrm{L}^{-1}$.

Para os valores de $\mathrm{pH}$ observa-se uma tendência de valores mais baixos em relação ao aumento da profundidade. Os maiores valores de $\mathrm{pH}$ foram encontrados no ponto 1 e os menores foram encontrados no ponto 3 (Figura 3f).

Pode-se considerar que os valores obtidos para a condutividade elétrica apresentam uma uniformidade ao longo da coluna d'água. O ponto 1 apresenta maiores valores (máximo de $166 \mu \mathrm{S} . \mathrm{cm}^{-1}$ ), os pontos 2 e 3 apresentam valores semelhantes (Figura $3 \mathrm{~h}$ )

Com relação aos teores de material em suspensão a tendência observada é de aumento em relação ao fundo para os pontos 1 e 3 , e redução no ponto 2 . Nos pontos 1 e 2 foram obtidas as maiores concentrações (máximo de $7,3 \mathrm{mg} . \mathrm{L}^{-1}$ para o ponto $1 \mathrm{e} 7,6 \mathrm{mg} . \mathrm{L}^{-1}$ para o ponto 2) (Figura $4 b$ ).

As maiores concentrações de matéria orgânica em suspensão foram encontradas, em média, no ponto 2 (máximo de $6,6 \mathrm{mg} . \mathrm{L}^{-1}$ ), as menores concentrações foram encontradas no ponto 3. Não foi estabelecido um padrão vertical para esta variável (Figura 4d).

Não foi observado um padrão vertical definido relativo aos teores de sólidos totais. $\mathrm{O}$ valor máximo determinado foi no ponto 1 , da ordem de $111 \mathrm{mg} . \mathrm{L}^{-1}$ (Figura 4f).

A maior profundidade de desaparecimento do disco de Secchi foi encontrada no ponto 2 $(1,18 \mathrm{~m})$. No ponto $1 \mathrm{o}$ valor foi de $1,02 \mathrm{~m}$ e $1,1 \mathrm{~m}$ no ponto 3 .

Em relação às concentrações de clorofila-a, não foi observado um padrão geral de distribuição. Há diminuição em relação ao fundo no ponto 1; aumento em relação ao fundo no ponto 3, com concentração igual a zero a 1 metro de profundidade. No ponto 2 observam-se altas concentrações na região superficial, e uma significativa redução nas concentrações a partir dos 4 metros de profundidade. Os maiores valores foram encontrados no ponto 2 (29,03 $\left.\mu \mathrm{g} . \mathrm{L}^{-1}\right)$ (Figura 5b). A distribuição de feofitina apresenta padrão inverso (Figura 5d).

As concentrações de silicato se mostram homogêneas no gradiente vertical. $\mathrm{O}$ ponto 1 apresenta as maiores concentrações (em torno de $411,55 \mu \mathrm{g} . \mathrm{L}^{-1}$ ), nos pontos 2 e 3 as concentrações são similares (em torno de $259,7 \mu \mathrm{g} . \mathrm{L}^{-1}$ ) (Figura $5 \mathrm{f}$ ).

Observa-se tendência a aumento das concentrações de amônio em relação ao fundo (Figura 6, b). Os maiores valores foram encontrados no ponto 1 (máximo de 39,98 $\mu \mathrm{g} . \mathrm{L}^{-1}$ ) e os menores no ponto 2 (máximo de $6,65 \mu \mathrm{g} . \mathrm{L}^{-1}$ ). Para as concentrações de nitrato observa-se uma leve tendência a redução em relação ao fundo (Figura $6 \mathrm{c}$ ). Os maiores valores foram encontrados no ponto 3 (máximo de $80,96 \mu \mathrm{g}$. $\mathrm{L}^{-1}$ ). As concentrações de nitrito, fosfato e fósforo total encontradas estão abaixo dos limites de detecção dos métodos.

Em relação à concentração de material em suspensão inorgânico, observa-se tendência de aumento das concentrações em relação ao fundo nos três pontos amostrados. Os maiores valores foram encontrados no ponto $3\left(2,14 \mathrm{mg} . \mathrm{L}^{-1}\right)$, à profundidade de 14 metros (Figura $4 \mathrm{~h}$ ).

A ACP obtida com as variáveis coletadas no mês de outubro (Figura 8) enfatizou a heterogeneidade espacial no reservatório, uma vez que os pontos representativos das profundidades amostradas em cada estação de coleta estão agrupados, indicando que cada ponto de amostragem possui características limnológicas distintas. 


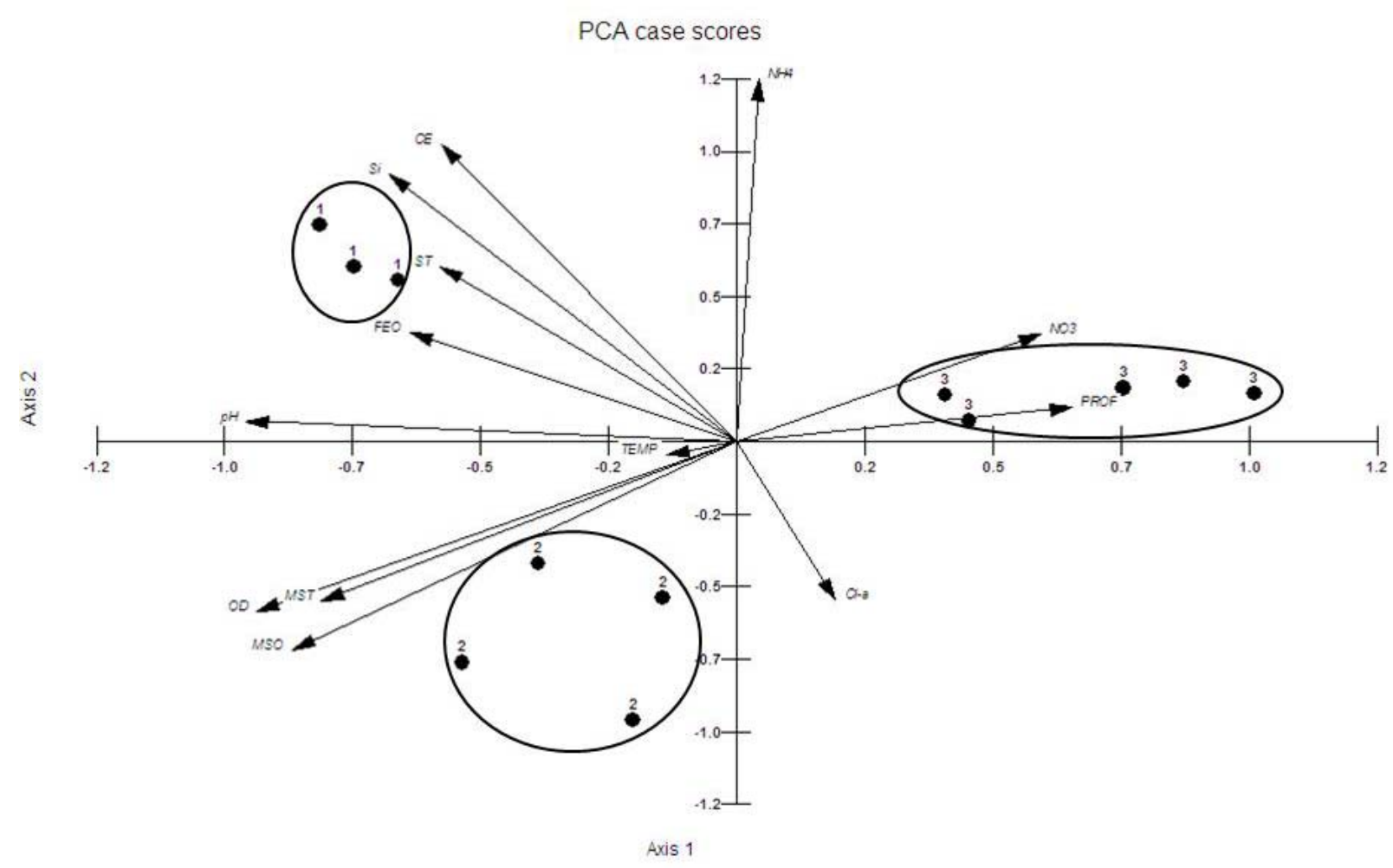

Figura 8. Resultado gráfico da Análise de Componentes Principais (ACP), obtida em três pontos de amostragem no Reservatório Rio das Pedras, em 07/10/04, onde: profundidade $=$ PROF; temperatura $=$ TEMP; condutividade elétrica $=\mathrm{CE}$; sólidos totais $=\mathrm{ST}$; clorofila-a $=\mathrm{Cl}$-a; feofitina $=\mathrm{FEO}$; amônio $=$ $\mathrm{NH} 4$; silicato $=\mathrm{Si}$; oxigênio dissolvido $=\mathrm{OD}$; material em suspensão total $=\mathrm{MST}$; material em suspensão orgânico $=\mathrm{MSO}$; potencial hidrogeniônico $=\mathrm{pH}$; nitrato $=$ NO3. Observa-se em destaque (circulado) as profundidades representativas dos três pontos de amostragem, 1, 2 e 3, que se encontram agrupadas, indicando a heterogeneidade espacial no reservatório. silicato.

A ACP apresentou correlação positiva entre sólidos totais, condutividade elétrica e

\subsection{Comparação entre as duas coletas}

Comparando-se os valores de temperatura e a amplitude de variação obtidas nas duas coletas pode-se discutir que houve estratificação térmica da água no mês de março e tendência a isotermia em outubro (Figura $3 a$ e $3 b$ ). Observa-se estratificação química do oxigênio em março e homogeneidade ao longo da coluna d'água em outubro (Figura 3c e 3d).

Em relação ao $\mathrm{pH}$, aos teores de material em suspensão e a concentração de matéria orgânica não há um padrão sazonal estabelecido nos valores encontrados.

No segundo período de coleta foram encontrados maiores valores de profundidade de Secchi, de condutividade elétrica, maiores teores de sólidos totais presentes na água e maiores concentrações de silicato.

Os valores de concentração de clorofila-a sugerem distribuição desigual no mês de outubro (ausência de padrão vertical) e tendência à estratificação biológica no mês de março.

Um panorama geral dos valores obtidos nos dois períodos amostrados pode ser verificado na Tabela 1. 
PADIAL, P. R.; POMPÊO, M.; MOSCHINI-CARLOS, V. Heterogeneidade espacial e temporal da qualidade da água no reservatório Rio das Pedras (Complexo Billings, São Paulo). Ambi-Agua, Taubaté, v. 4, n. 3, p. 35-53, 2009. (doi:10.4136/ambi-agua.101)

Tabela 1. Valores máximos e mínimos encontrados nas variáveis limnológicas nos três pontos amostrados, nos meses de março e outubro, onde: $\mathrm{CE}=$ condutividade elétrica; $\mathrm{OD}=$ oxigênio dissolvido; $\mathrm{ST}=$ teor de sólidos totais; MST = teor de material em suspensão; MSO = teor de matéria orgânica em suspensão; MSI = teor de matéria inorgânica em suspensão; DS = profundidade do disco de Secchi.

\begin{tabular}{|c|c|c|c|c|c|c|c|c|c|c|c|c|}
\hline \multirow{3}{*}{ Variáveis } & \multicolumn{6}{|c|}{ Março } & \multicolumn{6}{|c|}{ Outubro } \\
\hline & \multicolumn{2}{|c|}{ Ponto1 } & \multicolumn{2}{|c|}{ Ponto2 } & \multicolumn{2}{|c|}{ Ponto3 } & \multicolumn{2}{|c|}{ Ponto1 } & \multicolumn{2}{|c|}{ Ponto2 } & \multicolumn{2}{|c|}{ Ponto3 } \\
\hline & Min. & Max. & Min. & Max. & Min. & Max. & Min. & Max. & Min. & Max. & Min. & Max. \\
\hline Temp. $\left({ }^{\circ} \mathrm{C}\right)$ & 22,6 & 24,3 & 21,5 & 24,1 & 21,4 & 23,2 & 18,1 & 18,7 & 18,1 & 18,6 & 18,2 & 18,6 \\
\hline $\mathrm{pH}$ & 6,97 & 7,69 & 6,55 & 8,63 & 6,08 & 8,07 & 8,04 & 8,57 & 7,73 & 8,27 & 7,26 & 8,01 \\
\hline $\mathrm{CE}\left(\mu \mathrm{S} . \mathrm{cm}^{-1}\right)$ & 105 & 117 & 88 & 102,5 & 100,8 & 114,4 & 162,7 & 166 & 144,6 & 150,7 & 147,5 & 150,4 \\
\hline $\mathrm{OD}\left(\mathrm{mg} . \mathrm{L}^{-1}\right)$ & 7,33 & 8,83 & 5,32 & 9,04 & 0,68 & 8,61 & 7,11 & 7,16 & 7,4 & 8,1 & 4,4 & 6,1 \\
\hline OD (\% sat.) & 94 & 115 & 67 & 118 & 8,5 & 110 & 82,7 & 84,9 & 86,5 & 96,1 & 51,2 & 72,5 \\
\hline ST (mg.L $\left.{ }^{-1}\right)$ & 81 & 84 & 68,5 & 77,5 & 72,5 & 79 & 98,5 & 111 & 89 & 102 & 87,5 & 98,5 \\
\hline $\operatorname{MST}\left(\mathrm{mg} \cdot \mathrm{L}^{-1}\right)$ & 7,75 & 9 & 5,5 & 9 & 2,75 & 5,5 & 6,2 & 7,3 & 7,1 & 7,6 & 4,3 & 5,8 \\
\hline $\operatorname{MSO}\left(\mathrm{mg} . \mathrm{L}^{-1}\right)$ & 6,5 & 8,5 & 2,75 & 7,5 & 2,75 & 5,5 & 5,06 & 5,59 & 5,8 & 6,6 & 3,66 & 4,3 \\
\hline MSI (mg.L $\left.{ }^{-1}\right)$ & 0,5 & 1,25 & 0,25 & 2,75 & 0 & 0 & 1,0 & 1,71 & 1,0 & 1,3 & 0,15 & 2,14 \\
\hline $\begin{array}{l}\text { Amônio } \\
\left(\mu \mathrm{g} . \mathrm{L}^{-1}\right)\end{array}$ & - & 112,3 & - & 33,4 & 2,28 & 598 & 36,3 & 39,9 & 5,49 & 6,65 & 23,05 & 29,43 \\
\hline Silicato $\left(\mu \mathrm{g} . \mathrm{L}^{-1}\right)$ & 204,7 & 258,7 & 101,1 & 173,8 & 150,7 & 193,7 & 400,8 & 428,4 & 248,8 & 273 & 232,3 & 288,5 \\
\hline $\begin{array}{l}\text { Clorofila-a } \\
\left(\mu \mathrm{g} . \mathrm{L}^{-1}\right)\end{array}$ & 0,69 & 25,4 & 0 & 21,28 & 0,69 & 11,67 & 1,57 & 17,26 & 0 & 29,03 & 0 & 17,26 \\
\hline $\begin{array}{l}\text { Profundidade } \\
\text { máxima (m) }\end{array}$ & \multicolumn{2}{|c|}{4,8} & \multicolumn{2}{|c|}{6,7} & \multicolumn{2}{|c|}{15,5} & \multicolumn{2}{|c|}{5,0} & \multicolumn{2}{|c|}{7,5} & \multicolumn{2}{|c|}{16,5} \\
\hline DS (m) & \multicolumn{2}{|c|}{0,75} & \multicolumn{2}{|c|}{0,76} & \multicolumn{2}{|c|}{1,04} & \multicolumn{2}{|c|}{1,02} & \multicolumn{2}{|c|}{1,18} & \multicolumn{2}{|c|}{1,10} \\
\hline
\end{tabular}

Além da heterogeneidade espacial demonstrada pela ACP (Figuras 7 e 8), a análise conjunta (março e outubro) demonstrou a existência de heterogeneidade temporal no reservatório, uma vez que os pontos representando as diferentes profundidades e os dois períodos de amostragem de cada estação de coleta encontram-se agrupados, principalmente os pontos representativos do mês de outubro, como observado na Figura 9.

A PCA (Figura 9) estabelece correlação positiva entre clorofila-a, concentração de oxigênio dissolvido e $\mathrm{pH}$; condutividade elétrica, concentração de sólidos totais e silicato; profundidade e amônio; e correlação negativa entre temperatura e concentração de silicato.

\section{DISCUSSÃO}

Quando as diferenças de temperatura geram camadas d'água com diferentes densidades há a formação de uma barreira física, impedindo a mistura. Dessa forma o calor não se distribui uniformemente, criando a condição de estratificação térmica (Esteves, 1998). No entanto, a variação da densidade em função da temperatura não ocorre de maneira linear; com a elevação da temperatura da água, as diferenças de densidade tornam-se cada vez maiores. Segundo Esteves (1998), em ecossistemas aquáticos com níveis de temperatura superiores a $20^{\circ} \mathrm{C}$, não há necessidade de grande amplitude térmica entre as sucessivas camadas para que se processe o fenômeno da estratificação. Para regiões tropicais variações de $1^{\circ} \mathrm{C}$ por metro de coluna de água já confere substancial diferença de densidade entre a massa de água superior e inferior $(1 \mathrm{~m})$ para caracterizar estratificação térmica (Lampert e Sommer, 1997). No reservatório em estudo, no mês de março, com temperaturas variando entre $21^{\circ} \mathrm{C}$ e $24^{\circ} \mathrm{C}$, observou-se o fenômeno da estratificação térmica. No mês de outubro, com temperaturas em torno de $18^{\circ} \mathrm{C}$, a coluna d'água se mostrou homogênea. 


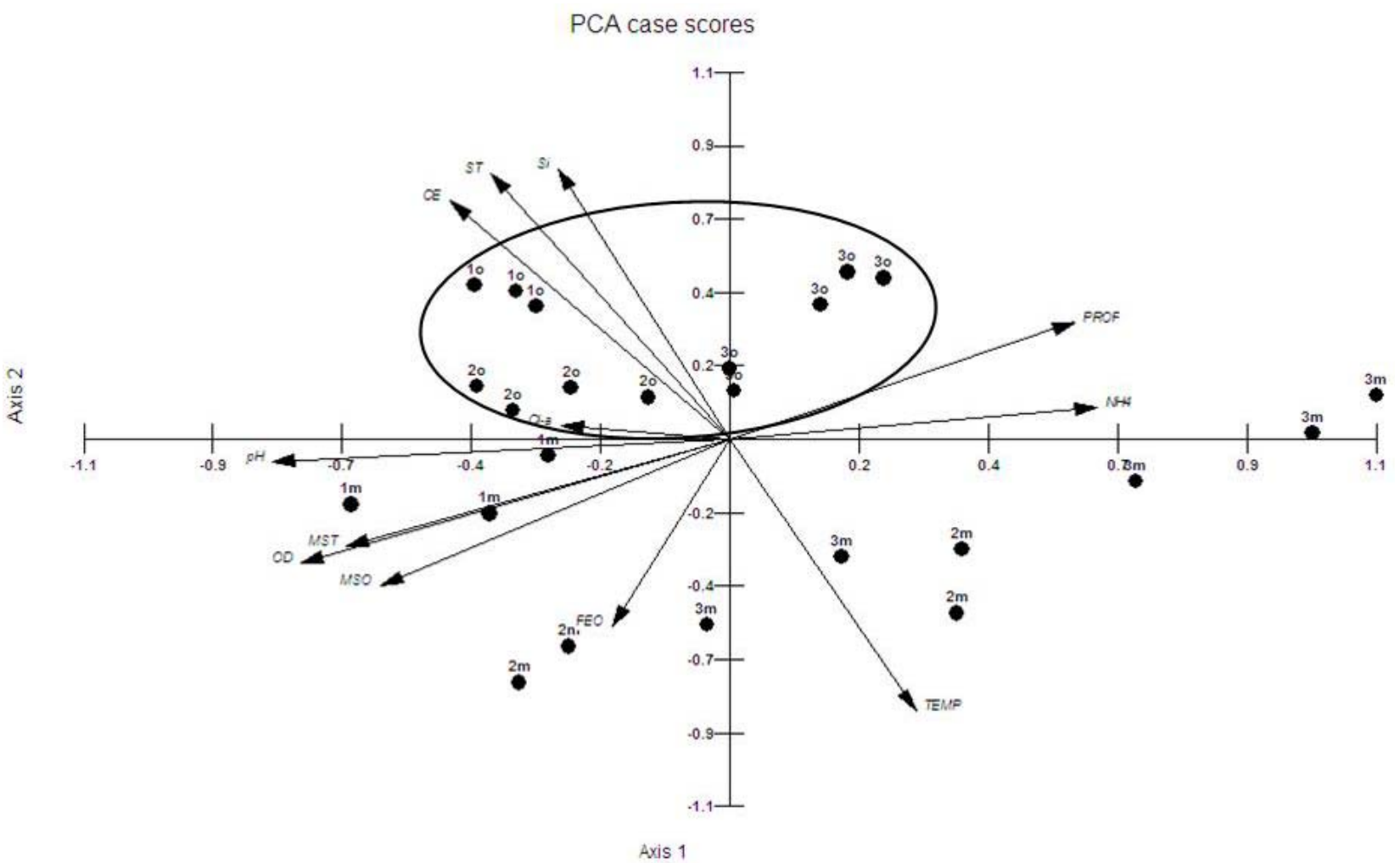

Figura 9. Resultado gráfico da Análise de Componentes Principais (ACP), obtida em três pontos de amostragem no Reservatório Rio das Pedras, em 12/03/04(m) e 07/10/04(o), onde: profundidade = PROF; temperatura $=\mathrm{TEMP}$; condutividade elétrica $=\mathrm{CE}$; sólidos totais $=\mathrm{ST}$; clorofila-a $=\mathrm{Cl}$-a; feofitina $=$ FEO; amônio $=$ NH4; silicato $=\mathrm{Si}$; oxigênio dissolvido $=\mathrm{OD} ;$ material em suspensão total $=$ MST; material em suspensão orgânico $=\mathrm{MSO}$; potencial hidrogeniônico $=\mathrm{pH}$. Observa-se em destaque (circulado) as profundidades representativas dos três pontos de amostragem, 1, 2 e 3, obtidos em outubro (o). O agrupamento destes pontos indica a heterogeneidade temporal no reservatório.

A estratificação térmica também provoca a formação de estratificações químicas e biológicas (Esteves, 1998).

Em muitos casos um gradiente decrescente de temperatura é seguido por um gradiente decrescente de oxigênio dissolvido (Tundisi, 1988). No epilímnio, as perdas de oxigênio são compensadas pela sua produção através da fotossíntese ou pela sua difusão a partir da atmosfera (Esteves, 1998), porém, devido à estratificação térmica, este gás não é distribuído para as camadas inferiores. No hipolímnio, as perdas de oxigênio podem ser atribuídas à intensa decomposição aeróbia de matéria orgânica e à respiração dos organismos (Lampert e Sommer, 1997). Dessa forma, estabelece-se um gradiente decrescente de oxigênio dissolvido. O padrão de distribuição vertical do oxigênio, no reservatório em estudo, foi o de completa oxigenação da coluna d'água durante o período de isotermia, com porcentagem de saturação variando entre $96,1 \%$ e $51,2 \%$. Os valores obtidos na primeira coleta (março) mostram que a concentração de oxigênio dissolvido está diretamente relacionada com o perfil térmico, evidenciando os processos de estratificação química, apresentando supersaturação na camada superficial (em torno de 115\%), decrescendo até saturações de $8,5 \%$ na maior profundidade amostrada $(14 \mathrm{~m})$. O processo de estratificação térmica e sua correlação com a concentração de oxigênio dissolvido foi descrito por Brunkow et al. (1988), para o reservatório de Itaipu.

O balanço de oxigênio e o balanço térmico têm importante papel nos processos do ciclo do nitrogênio. A concentração de oxigênio determina os processos de oxidação e redução dos compostos nitrogenados, e a temperatura acelera ou diminui a velocidade das reações químicas e dos processos biológicos (Schafer, 1984). 
O íon amônio é o produto final da decomposição (aeróbia e anaeróbia) da matéria orgânica dissolvida e particulada por bactérias heterotróficas, processo conhecido como amonificação (Schafer, 1984). Portanto, quanto maiores os teores de matéria orgânica, maiores serão as taxas de amonificação. Estudos laboratoriais demonstraram que a amonificação ocorre preferencialmente em ambientes anóxicos (Schafer, 1984). Outro processo relacionado com a formação do íon amônio é a denitrificação incompleta do nitrato. A denitrificação é estritamente anaeróbia. Na denitrificação completa há a redução do nitrato ao nitrogênio molecular (gasoso) (Schafer, 1984).

Em relação ao metabolismo do nitrato nos ecossistemas aquáticos, outro processo importante é a nitrificação, que consiste na oxidação biológica de compostos nitrogenados orgânicos ou inorgânicos reduzidos a nitrato (Esteves, 1998). Uma das formas de nitrificação é a transformação do íon amônio em nitrato, realizada por dois gêneros de bactérias. $\mathrm{O}$ processo em questão é predominantemente aeróbio.

Diante do panorama acima estabelecido, percebe-se que os processos de nitrificação e denitrificação são acoplados, e dependentes do balanço de oxigênio no meio. Em condições anaeróbias, os processos de amonificação da matéria orgânica e denitrificação são favorecidos, como conseqüência há aumento das concentrações do íon amônio e redução das concentrações de nitrato. Fenômeno oposto é observado com a oxigenação da coluna d'água e favorecimento do processo de nitrificação. As concentrações de oxigênio encontradas no hipolímnio dos pontos amostrados na primeira coleta são inversamente relacionadas às concentrações de amônio, sugerindo a ocorrência dos processos acima citados, sendo provavelmente a estratificação térmica da coluna d'água a principal causa de estratificação química do íon amônio. As baixas concentrações de amônio na superfície também estão associadas à sua preferencial assimilação pelos organismos fotossintetizantes, em detrimento das outras formas inorgânicas de nitrogênio (Esteves, 1998). A correlação positiva entre profundidade e amônio é corroborada pela $\mathrm{ACP}$. O favorecimento da decomposição da matéria orgânica (amonificação), ocasionado pelas altas temperaturas (quando comparadas à segunda coleta), somado aos fatores citados pode explicar as baixas concentrações de nitrato e nitrito encontradas neste período (abaixo dos níveis de detecção do método), onde grande parte dos compostos inorgânicos nitrogenados estava sob a forma de íon amônio. Na segunda coleta, quando comparadas às concentrações de nitrato e amônio, são observadas maiores concentrações de nitrato, favorecidas pela oxigenação do meio. Porém, com o pequeno gradiente de saturação de oxigênio em relação ao fundo, pode-se perceber a diminuição do nitrato em perfil vertical, associada a um aumento recíproco de amônio. O nitrito ocorre nas águas como um componente intermediário, resultante de redução bacteriana do nitrato (nitrificação) (Carmouze, 1994). As baixas concentrações deste nutriente na primeira coleta podem ser explicadas pelo não favorecimento do processo de nitrificação nesse período; a natureza intermediária deste composto pode explicar suas baixas concentrações na segunda coleta.

A dinâmica do ciclo do nitrogênio pode explicar, em parte, a distribuição e concentrações das formas nitrogenadas determinadas neste trabalho, entretanto outros fatores, como o aporte alóctone de nutrientes e a assimilação dos compostos pelos organismos autotróficos, não podem ser desconsiderados.

Altas concentrações de nutrientes no meio traduzem excesso de importação de nutrientes e coincidem, geralmente, com situações de eutrofização avançada. Porém, não se pode chegar, obrigatoriamente, à conclusão inversa quando se medem baixas concentrações de nutrientes nas águas (Carmouze, 1994). As baixas concentrações de nutrientes podem refletir as altas taxas de assimilação dos mesmos pela biota, sendo comum encontrar ecossistemas que apresentam altas biomassas planctônicas e elevadas taxas metabólicas (produção e mineralização), enquanto que as concentrações de nitrato, amônio e ortofosfato são muito 
reduzidas (Carmouze, 1994). Raciocínio semelhante pode ser conduzido no reservatório em estudo em relação aos nutrientes ortofosfato e fósforo total, e também de algumas formas nitrogenadas. As concentrações obtidas (abaixo dos níveis de detecção dos métodos) nas duas épocas do ano podem ser explicadas pela pronta assimilação destes pelos organismos fotossintetizantes. De acordo com a CETESB (2008), em relatórios anuais de qualidade da água, teores de clorofila acima de $11 \mu \mathrm{g} . \mathrm{L}^{-1}$, já conferem caráter de alta trofia, estando no limite inferior do nível eutrófico. Assim, neste trabalho, os teores de clorofila relativamente altos na porção superior da massa de água corroboram a afirmação da pronta assimilação dos nutrientes pelos organismos fotossintéticos.

As interações biológicas têm influência sobre o ciclo de todos os nutrientes num ecossistema aquático, sendo muito difícil identificar um fator limitante para o desenvolvimento dos organismos. Mas, além disto, outro fator de fundamental importância na dinâmica de nutrientes é o processo de sedimentação. Segundo Esteves (1998), elevados níveis de oxigênio e temperatura favorecem a precipitação do fósforo, nitrogênio e outros elementos no sedimento. Dessa maneira, reduzidas concentrações de nutrientes são observadas na coluna d'água. A correlação negativa obtida na ACP entre temperatura e concentração de silicato corrobora a ocorrência do processo de sedimentação desse nutriente, podendo explicar suas menores concentrações no mês de março.

A presença ou ausência de oxigênio influi decisivamente nas comunidades aquáticas (Schafer, 1984). A evidência da estratificação biológica gerada pela estratificação química do oxigênio pôde ser nitidamente observada no reservatório Rio das Pedras, analisando-se as concentrações de clorofila-a obtidas. No período de março, os organismos se distribuíram preferencialmente nas menores profundidades; já no segundo período estudado, devido às condições mais homogêneas da coluna d'água, não houve um padrão de distribuição preferencial da comunidade fitoplanctônica, principalmente na zona da barragem (ponto 3). Andrade et al. (1988) observaram padrão semelhante em estudo no reservatório de Itaipu. As maiores profundidades do disco de Secchi encontradas no mês de outubro estão relacionadas ao padrão citado, uma vez que foram notadas grandes diferenças na zona fótica. $O$ padrão encontrado no ponto 3, no mês de outubro é um bom indicativo da distribuição desigual da biomassa fitoplanctônica, pois este ponto é mais profundo, e localizado numa região de menor turbulência no reservatório, podendo ser chamada de zona lacustre, como definido por Thorton et al. (1990). A clorofila-a representa um dos melhores indicadores da biomassa fitoplanctônica. A determinação da feofitina na mesma amostra é indispensável por representar um fator de correção da clorofila-a, e ser um indicador do estado físiológico do fitoplâncton. Numa população em declínio, o teor de clorofila-a diminui, enquanto seus produtos de degradação (feopigmentos) e os carotenóides aumentam (Margalef, 1967). A relação entre a estratificação biológica, representada pelas concentrações de clorofila-a, e concentração de oxigênio dissolvido foi corroborada pela correlação positiva obtida entre estas duas variáveis na ACP.

Os valores de $\mathrm{pH}$ encontrados, provavelmente refletem a atividade dos organismos fotossintetizantes, uma vez que a retirada de gás carbônico da água altera a alcalinidade, resultando em aumento nos valores de pH (Calijuri et al., 1999). Dessa forma, o padrão de diminuição do $\mathrm{pH}$ em relação ao fundo correlaciona-se com a zona fótica e realização da fotossíntese na porção superficial. No mês de março, o gradiente vertical é mais acentuado em relação ao mês de outubro, demonstrando relação direta entre os valores de $\mathrm{pH}$ e as concentrações de clorofila-a encontrados. Os valores de $\mathrm{pH}$ correlacionam-se positivamente com as concentrações de oxigênio dissolvido, com gradiente decrescente em relação ao fundo, sendo este padrão diretamente associado à realização da fotossíntese. A ACP obtida corrobora a correlação positiva entre as três variáveis ( $\mathrm{pH}$, oxigênio dissolvido e clorofila). 
Pelos resultados obtidos de condutividade elétrica, pode-se inferir que no segundo período de coleta havia uma maior concentração de íons no ambiente. As maiores concentrações de sólidos totais obtidas na segunda coleta podem estar diretamente correlacionadas com os maiores valores de condutividade elétrica obtidos neste período. A correlação positiva obtida pela ACP entre a condutividade elétrica, o teor de sólidos totais e as concentrações de silicato corrobora a relação entre estas variáveis.

Em relação à heterogeneidade espacial horizontal pode-se notar que no ponto 1 foram encontradas maiores concentrações de sólidos totais e silicato (nos dois períodos amostrados), e maiores concentrações de nitrito e amônio (no mês de outubro) e de matéria orgânica em suspensão (no mês de março). Estes valores podem correlacionar-se à proximidade deste ponto ao canal Billings-Pedras, demonstrando a influência do reservatório Billings nas variáveis limnológicas deste ponto. Os pontos representativos da estação de coleta 1 são os que apresentaram valores mais discrepantes pela ACP.

As maiores concentrações de material em suspensão total encontradas nos pontos 1 e 2 , nos dois períodos amostrados, relacionam-se à menor profundidade destes corpos d'água $(4,9$ $\mathrm{m}$ e $7 \mathrm{~m}$ respectivamente) em relação ao ponto $3(16 \mathrm{~m})$, que aumentam as probabilidades de ressuspensão do sedimento.

A morfometria do reservatório pode ser responsável por diferenças espaciais horizontais encontradas. Isto é observado porque a característica dendrítica pode gerar isolamento das massas d'água, compartimentando o reservatório (Tundisi, 1999). Esta heterogeneidade espacial também é vertical, como efeito das massas de águas superpostas durante o período de estratificação térmica. Neste processo os diferentes compartimentos formados podem apresentar dinâmica própria, com características físicas e químicas distintas; e o tempo de residência, assim como os afluentes e os usos do solo no entorno, tem ação direta na qualidade das águas dos locais.

De acordo com a Resolução CONAMA n ${ }^{\circ} 357 / 05$, relativo às variáveis estudadas neste trabalho e com base nos parâmetros estabelecidos pela Resolução, os limites estabelecidos para a Classe 3 são os seguintes: oxigênio dissolvido, em qualquer amostra, não inferior a 4 mg.L-1; pH entre 6,0 e 9,0; e quantidades máximas de $0,075 \mathrm{mg} . \mathrm{L}^{-1}$ de fosfato total, $10 \mathrm{mg} . \mathrm{L}^{-1}$ de nitrato, $1,0 \mathrm{mg} \cdot \mathrm{L}^{-1}$ de nitrito, entre $13 \mathrm{mg} \cdot \mathrm{L}^{-1}$ e $1,0 \mathrm{mg} \cdot \mathrm{L}^{-1}$ de nitrogênio amoniacal e $500 \mathrm{mg} \cdot \mathrm{L}^{-1}$ de sólidos totais.

De acordo com os usos múltiplos preponderantes no reservatório, diante dos limites citados, e dos resultados obtidos neste estudo, para o mês de outubro as águas do reservatório Rio das Pedras estão em conformidade com a Classe 3. No mês de março, não foram encontrados valores acima de $4 \mathrm{mg} \cdot \mathrm{L}^{-1}$ de oxigênio dissolvido em todas as amostras, pois no ponto 3, abaixo dos 5 metros de profundidade os valores estão abaixo do estabelecido, conferindo não conformidade para a Classe 3. Neste caso, os gradientes verticais impossibilitam os usos de água profunda do sistema.

\section{CONCLUSÕES}

A heterogeneidade temporal observada na massa de água do reservatório Rio das Pedras foi consequência principalmente das diferenças de temperatura observadas, que geraram estratificação térmica, seguida de química e biológica, no mês de março. As diferenças espaciais verticais também resultaram da estratificação térmica.

As maiores discrepâncias das características limnológicas, em relação ao padrão de distribuição espacial horizontal, foram obtidas no ponto 1. Comparativamente aos outros pontos de coleta, foram encontradas maiores concentrações de sólidos totais e silicato (nos dois períodos amostrados), maiores concentrações de nitrito e amônio (no mês de outubro) e de matéria orgânica em suspensão (no mês de março). A heterogeneidade do ponto 1 pode ser atribuída à influência das águas provenientes do reservatório Billings. A morfometria 
dendrítica do reservatório também pode ser considerada como um fator gerador de gradientes espaciais horizontais.

\section{AGRADECIMENTOS}

A FAPESP (proc. 02/13376-4) e EMAE - Empresa Metropolitana de Águas e Energia SA pelas informações e facilidades oferecidas.

\section{REFERÊNCIAS BIBLIOGRÁFICAS}

ANDRADE, L. F. L.; BRUNKOW, R. F.; XAVIER, C. F.; DOMINGUES, L. L. Fitoplâncton e características físico-químicas do rReservatório de Itaipu, Paraná - Brasil. In: Limnologia e Manejo de Represas. São Carlos: EESC-USP/ CRHEA/ ACIESP, 1988. 506p. (Série Monografias em Limnologia, 1, Tomo I)

BRAGA, B.; PORTO, M.; TUCCI, C. E. M. Monitoramento de quantidade e qualidade das águas. In: Águas doces no Brasil: capital eEcológico, uso e conservação. São Paulo: Escrituras , 1999. 717p.

BRASIL. Ministério do Meio Ambiente. Conselho Nacional do Meio Ambiente. Resolução CONAMA $\mathbf{n}^{0}$ 357. Classificação das águas doces, salobras e salinas do território nacional. Brasília: Diário Oficial da República Federativa do Brasil, 17 de março de 2005.

BRUNKOW, R. F.; ANDRADE, L. F.; XAVIER, C. F. Processo de estratificação térmica e de oxigênio dissolvido no Reservatório de Itaipu, Paraná-BR. In: Limnologia e Manejo de Represas. São Carlos: EESC-USP/ CRHEA/ ACIESP, 1988. 506p. (Série Monografias em Limnologia, 1, Tomo I)

CALIJURI, M. C.; DEBERDT, G. L. B.; MINOTI, R. T. A produtividade primária pelo fitoplâncton na Represa de Salto Grande (Americana, S.P). In: Ecologia de reservatórios: estrutura, função e aspectos sociais. Botucatu: FUNDIBIO: FAPESP, 1999. 800p.

CARDOSO-SILVA, S. Heterogeneidade espacial e a qualidade das águas superficiais do reservatório Guarapiranga. 2008. 100f. Dissertação (Mestrado em Ecossistemas Terrestres e Aquáticos) - Instituto de Biociências, Universidade de São Paulo, São Paulo, 2008.

CARMOUZE, J. P. O metabolismo dos ecossistemas aquáticos: fundamentos teóricos, métodos de estudo e análises químicas. São Paulo: Edgard Blucher, FAPESP, 1994. $253 p$.

COMPANHIA DE TECNOLOGIA DE SANEAMENTO AMBIENTAL - CETESB. Relatório de qualidade das águas interiores do Estado de São Paulo - 2007. São Paulo: Secretaria do Meio Ambiente, 2008. 540 p. (Série Relatórios)

EMPRESA METROPOLITANA DE ÁGUAS E ENERGIA S.A. - EMAE. 2004. Disponível em: <http://www.emae.sp.gov.br>. Acesso: 20 nov. 2004.

ESTEVES, F. A. Fundamentos de Limnologia. 2. ed. Rio de Janeiro: Interciência, 1998. $602 \mathrm{p}$.

GOlTERMAN, H. L.; CLYMO, R. S.; OHNSTAD, M. A. M. Methods for physical and chemical analysis of freshwaters. 20. ed. Oxford: Blackwell Scientific , 1978. 213p. 
KOROLEFF, F. Determination of Nutrients. In: Methods of seawater analysis. Verlag: Chemie Weinhein, 1976. p. 117-181.

LAMPERT, W.; SOMMER, U. Limnoecology: the ecology of lakes and streams. New York: Oxford University Press, 1997. 382 p.

LEGENDRE, P.; LEGENDRE, L. Numerical ecology. 2. ed. Amsterdam: Elsevier Science, 1998. 853p.

LORENZEN, C. J. Determination of chlorophyll and pheo-pigments: spectrophotometric equations. Limnol. Oceanogr., v. 12, p. 343-346, 1967.

MACKERET, J. F. H.; RAI, H.; TALLING, J. F. Water analysis: some revised methods for limnologists. Freshwater Biological Association, n. 36, p. 121, 1978.

MARGALEF, R. El ecosistema. In: Ecologia marine. Caracas: Fundación La Salle de Ciencias Naturales, 1967. p 377-453.

NOGUEIRA, V. P. Q. Qualidade da água em lagos e reservatórios. In: Hidrobiologia ambiental. São Paulo: Editora da Universidade de São Paulo: Associação Brasileira de Recursos Hídricos, 1999. 411p.

PORTO, M. F. A. Estabelecimento de parâmetros de controle da poluição. In: Hidrobiologia ambiental. São Paulo: Editora da Universidade de São Paulo: Associação Brasileira de Recursos Hídricos, 1991. 411p.

SCHAFER, A. Fundamentos de ecologia e biogeografia das águas continentais. Porto Alegre: Ed. da UFRGS, 1984. 532p.

SOLÓRZANO, L.; SHARP, J. H. Determination of total dissolved nitrogen in natural waters. Limnol. Oceanogr., v. 25, n. 4, p. 751-754, 1980.

STRICKLAND, J. D.; PARSONS, T. R. A. A manual of seawater analysis. Bull. Fish. Res. Bel. Can., v. 125, p. 1-185, 1960.

TEIXEIRA, C.; TUNDISI, J. G.; KUTNER, M. B. Plankton studies in a mangrove. II. The standing-stock and some ecological factors. Boletim do Instituto Oceanográfico, São Paulo, v. 24, p. 23-41, 1965.

THORTON, K. W.; KIMMEL, B. L.; PAYNE, F. E. Reservoir Limnology: ecological perspectives. New York: John Willey \& Sons, 1990. 246p.

TUNDISI, J. G. Produção primária, “Standing-Stock” e fracionamento do fitoplâncton na região lagunar de Cananéia. 1969. 131f. Tese (Doutorado) - Universidade de São Paulo, São Paulo, 1969.

TUNDISI, J. G. Impactos ecológicos da construção de represas: aspectos específicos e problemas de manejo. In: Limnologia e manejo de represas. São Carlos: EESC-USP/ CRHEA/ ACIESP, 1988. 506p. (Série Monografias em Limnologia, 1, Tomo I)

TUNDISI, J. G. Teoria, aplicações e perspectivas para usos múltiplos. In: Ecologia de reservatórios: estrutura, função e aspectos sociais. Botucatu: FUNDIBIO: FAPESP, 1999. 800p.

VALDERRAMA, J. C. The simultaneous analysis of total nitrogen and phosphorus in natural waters. Mar. Chem., v. 10, p. 109-122, 1981.

WETZEL, R. G.; LIKENS, G. E. Limnological analyses. 2. ed. New York: Springer-Verlag, 1991. 391p. 